\title{
An empirical study for ranking risk factors using linear assignment: A case study of road construction
}

\author{
Amin Foroughi $^{\mathbf{a}^{*}}$ and Mohammad Javad Esfahani ${ }^{\mathbf{b}}$
}

${ }^{a}$ Department of Industrial Engineering, Islamic Azad University, Naragh Branch, Naragh, Iran

${ }^{b}$ Young Researchers Club, Naragh Branch, Islamic Azad University, Naragh, Iran

\begin{tabular}{l}
\hline A R T I C L E I N F O \\
\hline Article history: \\
Received Aguest 16, 2011 \\
Received in Revised form \\
November, 11, 2011 \\
Accepted 12 November 2011 \\
Available online \\
21 November 2011 \\
\hline Keywords: \\
Linear assignment \\
Group decision making \\
Risk analysis \\
PMBOK
\end{tabular}

\section{Introduction}

Project risk management (PRM) plays an important competitive advantage for building sponsors, especially for those sponsors who take risks carefully, anticipate significant changes, and protect themselves from many events. Nevertheless, the realization of this advantage on design-intensive multi-disciplinary capital projects relies on the approach to the initial identification of risk. Chapman studied the necessary steps involved for assessment process of risk analysis by examining the quality of the identification and assessment process.

$\mathrm{Ng}$ and Loosemore (2007) discussed risk allocation in the private provision of public infrastructure and argued that many people benefit most from the private provision of public infrastructure when project risks are allocated properly between private and public sectors. They explained that there are * Corresponding author. Tel: +989183655625

E-mail addresses: amin.foroghi@gmail.com (A. Foroghi) 
many issues influencing this task such as technical, legal, political and economic complexity of infrastructure projects, etc. There are many cases where the risks are not predicted properly and we face with increase in costs, project delays and services. Ng and Loosemore (2007) investigated a case study of the controversial $\$ 920$ million New Southern Railway project in Sydney, Australia by analyzing the logic behind decisions on risk distributions between public and private sectors and their outcomes. They suggested a series of guidelines to better manage risks in such projects.

Thevendran and Mawdesley (2004) presented a comprehensive human risk factors in construction projects. They explained how construction practitioners played risk management and in particular human risks factors. They used a questionnaire and personal interviews with construction practitioners. They discovered that human risk factors are, according to the respondents, the most important construction risk, and emphasis the need to incorporate human risk factors into project risk management.

Baccarini and Archer (2001) explained the use of a methodology for the risk ranking of projects undertaken by the Department of Contract and Management Services (CAMS). Klein and Cork (1998) presented a method for assessment of the risk that a particular system such as an aircraft or computer, will not perform to its required performance characteristics when it is developed. The technique is based on decomposition of the system under assessment into a hierarchy of functionally specified assessment areas and in each area; the technique identifies technical risks, and techniques of assessing these risks. The framework presents a systematic structure for selecting assessment methods and integrating results of the use of selected methods into a coherent overall assessment of the system.

Ghosh and Jintanapakanont (2004) proposed a method for identifying and assessing the critical risk factors in an underground rail project in Thailand using a factor analysis approach. They identified nine critical factors with 35 items and the factors obtained through the factor analysis were assessed to gain better insight of their importance and impact on project management. Jannadi (2008) presented a comprehensive study for assessing risks associated with trenching works in Saudi Arabia. Isaksson and Stille (2005) presented a model for estimation of time and cost for tunnel projects based on risk evaluation using FMEA method (McDermott et al., 1996; PMI, 2004; Haimes, 2008).

$\mathrm{Xu}$ and Liu (2009) presented an information diffusion technique based on a grid system to assess regional environmental risk. The risk information on a single environmental risk source was diffused effectively using fuzzy set theory. Regional environmental risk values achieved from information diffusion clustered on classification criteria and different environmental risk levels and they were depicted in a spatial partition map. They explained that the results derived from this information diffusion method could help the local government of China optimize the distribution of industrial areas and build risk prevention measurements and emergency management procedures.

The reminder of this paper first identifies the risk factors in section 2 and details of the implementation of our proposed study are given in section 3. Finally, concluding remarks are given in the last to summarize the contribution of the paper.

\section{Road construction risk factors}

The proposed study of this paper considers the following four stages for assessing risk factors and they are explained in details in the following subsections.

\subsection{Questionnaire and feedback collection}

The first step is to gather all important factors, influencing the failure of a road construction through designing an appropriate questionnaire, distributing among experts and collecting their feedbacks. 


\subsection{Preliminary risk assessment}

In this step, we calculate the risk involved with each group. Let $P I R$ be the overall risk in each group, $P_{i}$ be the probability of an unwanted incident, $W_{i}$ be the performance of each project with $\sum_{i=1}^{4} w_{i}=1$ and $I_{i}$ be the impact of the incident. Therefore, we have,

$$
P I R=\sum_{i=1}^{4} W_{i} \times P_{i} \times I_{i}
$$

In our survey, there are four groups of decision makers and they separately send their feedbacks and we calculate six PIRs, leading us to use the following to calculate the overall primary index, $A P I R$.

$$
A P I R=\frac{\sum_{J=1}^{4}\left(n_{j} \times P I R_{j}\right)}{N},
$$

where $n_{j}$ is the number of people who participate in each group and $N=\sum_{i=1}^{4} n_{j}$.

\subsection{Secondary risk assessment}

As discussed earlier, the preliminary risk factors cannot help us find a complete figure on risk assessment and we need to consider some secondary risk factors.

Let $S I R$ be the overall secondary risk in each group, $P_{i}$ be the probability of an unwanted incident, $W_{i}$ be the performance of each project with $\sum_{i=1}^{4} w_{i}=1$ and $I_{i}$ be the impact of the incident. Therefore, we have,

$S I R=\sum_{i=1}^{4} W_{i} \times P_{i} \times I_{i}$

In our survey, there are four groups of decision makers and they separately send their feedbacks and we calculate six PIRs, leading us to use the following to calculate the overall secondary index, ASIR.

$A S I R=\frac{\sum_{J=1}^{4}\left(n_{j} \times S I R_{j}\right)}{N}$,

where $n_{j}$ is the number of people who participate in each group and $N=\sum_{i=1}^{4} n_{j}$.

\subsection{Risk assessment using linear assignment}

Now we can use the risk factors obtained from the previous steps as input for the following linear assignment problem formulation. 
$\max Z=\sum_{i=1}^{n} \sum_{k=1}^{n} \gamma_{i k} h_{i k}$

subject to

$\sum_{k=1}^{n} h_{i k}=1, \quad i=1, \cdots, n$

$\sum_{i=1}^{n} h_{i k}=1, k=1, \cdots, n$

$h_{i j}=0,1, \quad i, j=1, \cdots, n$

where $h_{i k}$ is a binary variable and when it receives a value one, it means that risk factor $i$ maintains $k^{\text {th }}$ ranking.

\section{Case study}

In this section, we present the implementation of the proposed model for a real-world case study of rail-road construction between the cities of Esfahan and Deligan.

\subsection{Deligan}

Deligan is a city in the capital of Delijan County, Markazi Province, Iran with the population of approximately 32,000 people and it is located $80 \mathrm{~km}$ (50 Mi) from Qom and $160 \mathrm{~km}$ (100 Mi) from Isfahan. The city is 300 kilometer away from the capital city of Iran and it is in the center of highways connecting various cities. Therefore, the city connects different cities and it plays an important role for domestic transportation.

\subsection{External and internal risk factors}

We have divided the risk factors into two groups of internal and external ones and they are given in Table 1.

Table 1

Internal (Primary) and external (Secondary) risk factors

\begin{tabular}{lllllll}
\multirow{2}{*}{ Internal } & 1.Political & 2.Social & 3.Economical & 4.Cultural & 5.Natural & 6.Domestic \\
& 7.Laws & 8.Regulation & 9.Planning & 10.Commitement & 11.development & \\
\hline \multirow{3}{*}{ External } & 12.Human & 13.Supply & 14.Project & 15.contractors & 16.Investment & 17.Contract \\
& Resource & chain & Management & & & \\
& 18.Operations & 19. Timing & 20.Marketing & 21. Industry & & \\
\hline
\end{tabular}

Our group decision-making method consists of four groups of 8, 5, 4 and 7 people and the feedbacks are gathered using Likert five point scale from very low to very high and the points for very low, low, average, high and very high are $0.1,0.3,0.5,0.7$ and 0.9 , respectively.

The feedbacks are collected based on PMBOK standard in terms of cost, time, quality and the likelihood of the occurrences. Table 2 shows details of the points for different items. 
Table 2

PMBOK standard in Likert Scale along with weight factors

\begin{tabular}{llll}
\hline \multirow{5}{*}{ Probability } & Less than 5\% & Very low & 0.1 \\
& Between 6\% to 25\% & Low & 0.3 \\
& Between 26\% to 50\% & Average & 0.5 \\
& Between 51\% to 70\% & High & 0.7 \\
& More than 71\% & Very high & 0.9 \\
\hline \multirow{5}{*}{ Time $\left(W_{1}=0.3\right)$} & Negligible & Very low & 0.1 \\
& Less than 5\% & Low & 0.3 \\
& Between 6\% to 10\% & Average & 0.5 \\
& Between 10\% to 20\% & High & 0.7 \\
& More than 20\% & Very high & 0.9 \\
\hline \multirow{5}{*}{ Cost $\left(W_{2}=0.42\right)$} & Negligible & Very low & 0.1 \\
& Less than 5\% & Low & 0.3 \\
& Between 6\% to 10\% & Average & 0.5 \\
& Between 10\% to 20\% & High & 0.7 \\
& More than 20\% & Very high & 0.9 \\
\hline \multirow{5}{*}{ Quality $\left(W_{3}=0.1\right)$} & Negligible & Very low & 0.1 \\
& Low & Low & 0.3 \\
& Needs approval & Average & 0.5 \\
& unacceptable & High & 0.7 \\
& Impossible to use & Very high & 0.9 \\
\hline \multirow{5}{*}{ Performance $\left(W_{4}=0.18\right)$} & Negligible & Very low & 0.1 \\
& Low & Low & 0.3 \\
& Needs approval & Average & 0.5 \\
& unacceptable & High & 0.7 \\
& Impossible to use & Very high & 0.9 \\
\hline
\end{tabular}

\subsection{Internal risk assessment}

Using the proposed method earlier, we have calculated the internal risk and the results are given in Table 3.

\section{Table 3}

Internal risk assessment

\begin{tabular}{lllllll}
\hline Risk & APIR1 & APIR2 & APIR3 & APIR4 & APIR & Rank \\
\hline 1 & 0.0348 & 0.1032 & 0.1674 & 0.336 & 0.159 & 19 \\
2 & 0.5544 & 0.077 & 0.5652 & 0.1698 & 0.344567 & 2 \\
3 & 0.14 & 0.369 & 0.0362 & 0.394 & 0.244492 & 12 \\
4 & 0.2136 & 0.2982 & 0.399 & 0.2484 & 0.272275 & 8 \\
5 & 0.0408 & 0.1434 & 0.1914 & 0.4018 & 0.192567 & 15 \\
6 & 0.316 & 0.0178 & 0.284 & 0.3618 & 0.2619 & 10 \\
7 & 0.0576 & 0.3276 & 0.315 & 0.1374 & 0.180025 & 17 \\
8 & 0.4572 & 0.4536 & 0.0942 & 0.0432 & 0.2752 & 9 \\
9 & 0.07 & 0.2016 & 0.081 & 0.3546 & 0.182258 & 16 \\
10 & 0.276 & 0.594 & 0.0876 & 0.3696 & 0.33815 & 3 \\
11 & 0.1704 & 0.0478 & 0.195 & 0.179 & 0.151467 & 20 \\
12 & 0.194 & 0.0642 & 0.1914 & 0.398 & 0.226025 & 13 \\
13 & 0.1764 & 0.4878 & 0.1776 & 0.2304 & 0.257225 & 11 \\
14 & 0.0248 & 0.6966 & 0.0492 & 0.0386 & 0.17285 & 18 \\
15 & 0.5292 & 0.1686 & 0.3626 & 0.1944 & 0.328658 & 4 \\
16 & 0.1344 & 0.198 & 0.4806 & 0.4312 & 0.291917 & 6 \\
17 & 0.0208 & 0.0288 & 0.4998 & 0.1638 & 0.144008 & 21 \\
18 & 0.306 & 0.4374 & 0.1662 & 0.185 & 0.274783 & 7 \\
\hline 19 & 0.6804 & 0.4592 & 0.0616 & 0.0608 & 0.350467 & 1 \\
\hline 21 & 0.6084 & 0.0524 & 0.322 & 0.1416 & 0.308683 & 5 \\
\hline
\end{tabular}




\subsection{External risk assessment}

Using the proposed method earlier, we have calculated the internal risk and the results are summarized in Table 4.

Table 4

External risk assessment

\begin{tabular}{llllll}
\hline Risk & ASIR1 & ASIR2 & APIR3 & APIR4 & APIR \\
\hline 1 & R18 & R1 & R13 & R18 & R15 \\
2 & R20 & R3 & R9 & R10 & R14 \\
3 & R2 & R9 & R1 & R11 & R1 \\
4 & R8 & R12 & R6 & R1 & R2 \\
5 & R4 & R21 & R7 & R2 & R6 \\
6 & R9 & R7 & R2 & R15 & R12 \\
7 & R7 & R19 & R11 & R7 & R17 \\
8 & R17 & R10 & R16 & R14 & R8 \\
9 & R3 & R16 & R18 & R13 & R510 \\
10 & R9 & R15 & R19 & R8 & R18 \\
11 & R13 & R4 & R20 & R3 & R11 \\
12 & R12 & R6 & R14 & R9 & R20 \\
13 & R6 & R13 & R10 & R16 & R16 \\
14 & R21 & R20 & R3 & R19 & R7 \\
15 & R10 & R5 & R4 & R6 & R9 \\
16 & R11 & R18 & R12 & R12 & R21 \\
17 & R15 & R8 & R5 & R5 & R4 \\
18 & R19 & R2 & R17 & R17 & R21 \\
19 & R5 & R14 & R15 & R20 & \\
20 & R14 & R17 & R21 & R28 & \\
\hline
\end{tabular}

\subsection{Input information of the assignment model}

Based on the results obtained from the previous part we calculate $\gamma_{i j}$ as follows,

Table 5

The values of $\gamma_{i j}$

\begin{tabular}{|c|c|c|c|c|c|c|c|c|c|c|c|c|c|c|c|c|c|c|c|c|c|}
\hline $\mathrm{R}$ & 1 & 2 & 3 & 4 & 5 & 6 & 7 & 8 & 9 & 10 & 11 & 12 & 13 & 14 & 15 & 16 & 17 & 18 & 19 & 20 & 21 \\
\hline 1 & .14 & .00 & .57 & .18 & .00 & .00 & .00 & .00 & .00 & .11 & .00 & .00 & .00 & .00 & .00 & .00 & .00 & .00 & .00 & .00 & .00 \\
\hline 2 & .00 & .00 & .11 & .36 & .18 & .21 & .00 & .00 & .00 & .00 & .00 & .00 & .00 & .00 & .00 & .00 & .00 & .14 & .00 & .00 & .00 \\
\hline 3 & .00 & .14 & .00 & .00 & .56 & .00 & .00 & .00 & . 11 & .00 & .18 & .00 & .00 & .21 & .00 & .00 & .00 & .00 & .00 & .00 & .00 \\
\hline 4 & .00 & .00 & .00 & .00 & .11 & .00 & .00 & .00 & .00 & .00 & .00 & .00 & .00 & .00 & .57 & .00 & .00 & .18 & .00 & .00 & .00 \\
\hline 5 & .00 & .00 & .00 & .00 & .00 & .00 & .00 & .00 & .00 & .36 & .00 & .00 & .00 & .00 & .14 & .00 & .37 & .00 & .11 & .00 & .00 \\
\hline 6 & .00 & .00 & .00 & .21 & .00 & .36 & .00 & .00 & .00 & .00 & .00 & .11 & .11 & .00 & .18 & .00 & .00 & .00 & .00 & .00 & .00 \\
\hline 7 & .00 & .00 & .00 & .00 & .21 & .14 & .27 & .00 & .00 & .00 & .00 & .00 & .00 & .00 & .00 & .00 & .36 & .00 & .00 & .00 & .00 \\
\hline 8 & .00 & .00 & .00 & .11 & .00 & .00 & .00 & .00 & .36 & .18 & .00 & .00 & .00 & .00 & .00 & .00 & .14 & .36 & .00 & .00 & .21 \\
\hline 9 & .00 & .21 & .14 & .00 & .00 & .11 & .00 & .00 & .00 & .00 & .00 & .18 & .00 & .00 & .00 & .00 & .00 & .00 & .00 & .00 & .00 \\
\hline 10 & .00 & .18 & .00 & .00 & .00 & .00 & .00 & .14 & .00 & .00 & .36 & .00 & .21 & .00 & .11 & .00 & .00 & .00 & .00 & .00 & .00 \\
\hline 11 & .00 & .00 & .18 & .00 & .00 & .00 & .21 & .00 & .00 & .00 & .00 & .00 & .36 & .00 & .00 & .11 & .00 & .00 & .00 & .00 & .14 \\
\hline 12 & .00 & .00 & .00 & .00 & .00 & .00 & .36 & .00 & .00 & .00 & .00 & .11 & .00 & .00 & .00 & .39 & .00 & .00 & .00 & .00 & .00 \\
\hline 13 & .21 & .00 & .00 & .00 & .00 & .00 & .00 & .00 & .18 & .00 & .00 & .00 & .14 & .00 & .00 & .00 & .00 & .00 & .36 & .00 & .00 \\
\hline 14 & .00 & .36 & .00 & .00 & .00 & .00 & .00 & .18 & .00 & .00 & .11 & .21 & .00 & .00 & .00 & .00 & .00 & .00 & .14 & .11 & .00 \\
\hline 15 & .36 & .00 & .00 & .00 & .00 & .18 & .00 & .00 & .00 & .14 & .00 & .00 & .00 & .00 & .00 & .00 & .11 & .00 & .21 & .00 & .00 \\
\hline 16 & .00 & .00 & .00 & .00 & .00 & .00 & .00 & .21 & .14 & .00 & .00 & .00 & .18 & .00 & .00 & .36 & .00 & .00 & .00 & .00 & .11 \\
\hline 17 & .00 & .00 & .00 & .00 & .00 & .00 & .00 & .57 & .00 & .00 & .00 & .00 & .00 & .00 & .00 & .00 & .21 & .00 & .18 & .14 & .00 \\
\hline 18 & .29 & .00 & .00 & .00 & .00 & .00 & .00 & .00 & .21 & .00 & .00 & .36 & .00 & .00 & .00 & .14 & .00 & .00 & .00 & .00 & .00 \\
\hline 19 & .00 & .00 & .00 & .00 & .00 & .00 & .14 & .00 & .00 & .21 & .00 & .00 & .00 & .18 & .00 & .00 & .11 & .00 & .00 & .00 & .36 \\
\hline 20 & .00 & .11 & .00 & .00 & .00 & .00 & .00 & .00 & .00 & .00 & .21 & .00 & .00 & .50 & .00 & .00 & .00 & .00 & .00 & .00 & .18 \\
\hline 21 & .00 & .00 & .00 & .00 & .14 & .00 & .00 & .00 & .00 & .00 & .00 & .00 & .00 & .11 & .00 & .00 & .00 & .00 & .00 & .75 & .00 \\
\hline
\end{tabular}




\subsection{Linear assignment model}

The proposed assignment problem given in Eq. (5) to Eq. (8) is solved using the input information of Table 5 and the optimal results are calculated. We have also used the data for ranking in terms of traditional method, which is a simple multiplication of risk ratio by its impacts and both results are summarized in Table 6

\section{Table 6}

The results of ranking in two methods of Linear assignment (LA) and Traditional method (Tr)

\begin{tabular}{llllllllllllllllllllll}
\hline Risk & 1 & 2 & 3 & 4 & 5 & 6 & 7 & 8 & 9 & 10 & 11 & 12 & 13 & 14 & 15 & 16 & 17 & 18 & 19 & 20 & 21 \\
\hline LA & 16 & 2 & 10 & 7 & 15 & 9 & 19 & 13 & 18 & 3 & 17 & 11 & 14 & 21 & 6 & 4 & 20 & 5 & 1 & 8 & 12 \\
$\operatorname{Tr}$ & 19 & 2 & 12 & 8 & 15 & 10 & 17 & 9 & 16 & 3 & 20 & 13 & 11 & 18 & 4 & 6 & 21 & 7 & 1 & 5 & 14 \\
\hline
\end{tabular}

The proposed model of this paper has different advantages against traditional model. First, it considers different factors, which helps remove systematic risk. The proposed model considers more than two factors and it would consider more realistic items, which makes the results more realistic.

\section{Conclusion}

We have presented a new risk assessment model based on the implementation of traditional linear assignment. The proposed model of this paper considered two groups of risk factors in terms of internal and external items. A group decision-making technique has been used to rank different risk factors and the results were used for a real-world case study of rail-road construction project located in a city of Deligan. The results of our study seem to perform better than traditional model, which uses only two single factors. In fact, the proposed model uses important factors such as cost, time, quality and other important items, which create a better image on different risks associated with the project.

\section{Acknowledgment}

The authors are grateful for constructive comments on earlier version of this paper, which makes the paper more readable.

\section{References}

Baccarini, D., \& Archer, R. (2001).The risk ranking of projects: a methodology. International Journal of Project Management, 19(3), 139-145.

Chapman, R. J. (2001). The controlling influences on effective risk identification and assessment for construction design management. International Journal of Project Management, 19(3), 147-160.

Ghosh, S. \& Jintanapakanont, J. (2004). Identifying and assessing the critical risk factors in an underground rail project in Thailand: a factor analysis approach. International Journal of Project Management, 22(8), 633-643.

Haimes, Y. (2008). Risk modeling, Assessment, and management. $3^{\text {rd }}$ ed., New York: John Wiley and Sons.

Klein, J.H., \& Cork, R. B. (1998). An approach to technical risk assessment. International Journal of Project Management, 16(6), 345-351.

Isaksson, T., \& Stille, H. (2005). Model for estimation of time and cost for tunnel projects based on risk evaluation. Rock Mechanic Rock Engineering, 38 (5), 373-398.

Jannadi, O.A. (2008). Risks associated with trenching works in Saudi Arabia. Journal of Building and Environment, 43(5), 776-781.

McDermott, R. E., Mikulak, R. J., \& Beauregard, M. R. (1996). The Basics of FMEA, New York: Quality resources.

Ng, A., \& Loosemore, M. (2007). Risk allocation in the private provision of public infrastructure. International Journal of Project Management, 25(1), 66-76. 
PMI (Project Management Institute) (2004). A Guide to the Project Management Body of Knowledge (PMBOK Guide), Pennsylvania, USA: Newtown Square.

Thevendran, V., \& Mawdesley, M.J. (2004). Perception of human risk factors in construction projects: an exploratory study. International Journal of Project Management, 22(2), 131-137.

$\mathrm{Xu}, \mathrm{L} .$, \& Liu, G. (2009). The study of a method of regional environmental risk assessment. Journal of Environmental Management, 90(11), 3290-3296. 